Tropical Journal of Pharmaceutical Research September 2020; 19 (9): 1941-1946

ISSN: $1596-5996$ (print); 1596-9827 (electronic) (C) Pharmacotherapy Group, Faculty of Pharmacy, University of Benin, Benin City, 300001 Nigeria

\title{
Mitigating effect of metformin on polycystic ovarian syndrome and insulin resistance in rats, and the mechanisms involved
}

\author{
Lanyawen Hu, Baimiao Wang*, Yingli Tao \\ Reproductive Immunology Department, Tongde Hospital of Zhejiang Province, Hangzhou, PR China \\ *For correspondence: Email: tqmxd5@163.com
}

Sent for review: 27 September 2019

Revised accepted: 14 August 2020

\begin{abstract}
Purpose: To study the effect of metformin on polycystic ovarian syndrome (PCOS) and insulin resistance (IR) in rats, and the mechanism involved.

Methods: Eighty healthy female SD rats, aged 6 weeks, were selected. Three groups of rats were used: model, metformin + PI3K inhibitor, and metformin groups, with 20/group. Testosterone, leutenizing hormone ( $\mathrm{LH})$, and follicle-stimulating hormone (FSH) were assayed by enzyme-linked assay (ELISA), while HOMA-IR was calculated from fasting blood sugar (FBG); the effect of metformin on the IR of PCOS rats was determined. The expressions of PI3K and AKT in ovaries and liver of rats in each group were assayed by Western blotting.

Results: Fasting blood glucose, fasting insulin, and insulin resistance index were markedly higher in model than in control rats, and also significantly higher in inhibitor-treated rats than in metformin rats ( $p$ $<0.05$ ). Relative to control, FSH level was higher, while levels of $L H, L H / F S H$ ratio and testosterone in the metformin group were significantly lower $(p<0.05)$. The expression levels of PI3K and AKT in the ovary and liver were reduced in the inhibitor group, relative to the levels in metformin-treated rats $(p<$ 0.05).

Conclusion: Metformin mitigates PCOS-linked ovarian changes and IR in rats via PIJKJAKT route. These findings may be useful in the design of new drugs.
\end{abstract}

Keywords: Metformin, Polycystic ovary syndrome, Leutenizing hormone, Insulin resistance, Fasting blood sugar, Follicle-stimulating hormone

\begin{abstract}
This is an Open Access article that uses a fund-ing model which does not charge readers or their institutions for access and distributed under the terms of the Creative Commons Attribution License (http://creativecommons.org/licenses/by/4.0) and the Budapest Open Access Initiative (http://www.budapestopenaccessinitiative.org/read), which permit unrestricted use, distribution, and
\end{abstract} reproduction in any medium, provided the original work is properly credited.

Tropical Journal of Pharmaceutical Research is indexed by Science Citation Index (SciSearch), Scopus, International Pharmaceutical Abstract, Chemical Abstracts, Embase, Index Copernicus, EBSCO, African Index Medicus, JournalSeek, Journal Citation Reports/Science Edition, Directory of Open Access Journals (DOAJ), African Journal Online, Bioline International, Open-J-Gate and Pharmacy Abstracts

\section{INTRODUCTION}

Polycystic ovary syndrome (PCOS) is a disease caused by abnormal endocrine metabolism which is characterized by ovulation dysfunction/loss, and hyperandrogenemia. It is mainly manifested as irregular menstrual cycle, infertility, insulin resistance (IR) and polycystic ovarian changes. It is the most common endocrine disease in women [1]. At present, PCOS occurs in about $10 \%$ of the total number of women in the world, and is increasing year by year. Thus, PCOS has become an important issue affecting women's health [2]. It has been found that the development of PCOS is closely related to IR. Insulin resistance (IR) not only 
upsets the balance between glucose and lipid metabolism in PCOS patients, but also causes disorder in the regulation of reproductive endocrine hormones [3]. Research on pathogenesis of PCOS suggest that the development of IR in PCOS patients has an important relationship with the PI3K/AKT route [4]. At present, metformin is considered the firstline drug in the treatment of IR and glucose intolerance. It ameliorates reproductive endocrine disorders and metabolic abnormalities in patients, promotes intestinal absorption of glucose, inhibits output of liver glycogen, and reduces liver glycogenesis [5]. The purpose of the present investigation was to study the mitigating influence of metformin on polycystic ovarian changes and IR in PCOS rats, and the underlying mechanism.

\section{EXPERIMENTAL}

\section{Animals}

Eighty healthy female SD rats aged 6 weeks (mean weight $=195 \pm 25 \mathrm{~g}$ ) were obtained from Shanghai Ruitaimo Biotech. Co. Ltd \{production license SCXK (Shanghai) 2016-0001\}.

This study received approval from the Animal Ethical Committee of Tongde Hospital of Zhejiang Province, and it was implemented in line with the Principles of Laboratory Animal Care [6].

\section{Main equipment and reagents}

The instruments and reagents used, and their suppliers (in brackets) were: electronic balance (Shenyang Longteng Electronic Co. Ltd, Model: ESJ-4B); biological microscope (Shanghai Nuochai Trading Co. Ltd., model: FL-306A); autoclave (Shandong Boke Gas Industry Co. Ltd., model: BKQ-B50II); paraffin slicer (Hubei Taiwei Technology Co. Ltd., model: R139); constant temperature water bath box (Suzhou Peiying Experimental Equipment Co. Ltd., model: HWS-20); electronic blood glucose meter (Shenzhen zhuangshengtang Pharmaceutical Co. Ltd., model: GLM-76); low temperature refrigerator (Shanghai Kaizhen Instrument Equipment Co. Ltd., model: MDF-86V188E); centrifuge (Guangzhou Jidi Instrument Co. Ltd., model: JIDI-4D-WS); metformin (Shanghai Shiguibao Pharmaceutical Co. Ltd., production batch No.: 20173370, specification : $0.5 \mathrm{~g} \times 20$ s); $0.9 \% \mathrm{NaCl}$ injection (Sichuan Kelun Pharm. Co. Ltd., production batch No.: 20176626, specification: $100 \mathrm{~mL}$ ), and glucose (Henan Kelun Pharmaceutical Co. Ltd., production batch No.: 41022311, specification: $100 \mathrm{~mL}$ ).

\section{Establishment of PCOS IT model and animal grouping}

The rats were fed adaptively for one week at a temperature of $24 \pm 2{ }^{\circ} \mathrm{C}$ and $52 \pm 18 \%$ humidity. They were allowed free access to feed and water. Three groups of rats were used, with 20 control rats and 40 rats in model group. Rats in the model group were given letrozole $(1 \mathrm{mg} / \mathrm{kg}$ daily, in $1 \mathrm{~mL} 1 \%$ sodium carboxymethylcellulose) via gavage for 30 days, and cytological changes of vaginal exfoliation were monitored using methylene blue staining. Vaginal epithelial cells of PCOS rats were keratinized for 10 days. After fasting for $10 \mathrm{~h}$, FBG and insulin were measured with FBG meter, and HOMA-IR was calculated. Rats with established PCOS IR were assigned to model, metformin + PI3K inhibitor, and metformin groups, with 20 rats/group. Rats in the model group were fed high fat diet.

\section{Treatment indices}

Blood $(5 \mathrm{~mL})$ was taken from the abdominal aorta of each rat, and serum samples were obtained after centrifugation at the speed of 3000 rpm. The serum samples were then cryopreserved in the refrigerator at $-80^{\circ} \mathrm{C}$ prior to assay of biochemical parameters. The level of HOMAIR was calculated using Eq 1.

HOMA-IR $=[(F B G \times F I N S) / 22.5]$

from which the effect of metformin on IR of PCOS rats was determined.

The complete bilateral ovaries and livers were taken out, weighed, and their appearance was examined. The ovaries were rinsed with phosphate buffer and stored in a low temperature refrigerator. A portion of ovary was placed in the test tube, fixed with $4 \%$ formaldehyde, and processed into paraffin sections. The ovarian tissue sections were stained with H\&E staining method, and their histological morphologies were examined under a light microscope. Luteinizing hormone (LH), FSH and testosterone (T) were assayed with ELISA, and LH/FSH ratio was determined. The kit and serum samples were placed at room temperature for 20min, diluted 1:5 with distilled water, dissolved using the doubling dilution method, and used for standard curve. Serum sample $(100 \mu \mathrm{L})$ was added to the reaction well and the universal diluent was added to the blank well. The reaction well was sealed and placed in an incubator at $37^{\circ} \mathrm{C}$ for $90 \mathrm{~min}$. Biotinylated antibody working solution was prepared $30 \mathrm{~min}$ in advance, and the plate was cleaned. Then, $350 \mu \mathrm{L}$ of washing solution was injected into each well. The interval between 
injection and suction was 15 seconds. Subsequently, biotinylated antibody diluent was added to the blank well, and working solution was added to the other well. The wells were sealed again and incubated in the incubator at $37^{\circ} \mathrm{C}$ for $60 \mathrm{~min}$. The microplate reader was open, the parameters were set, the absorbance was read at $450 \mathrm{~nm}$.

The expressions of PI3K and AKT in ovaries and livers of rats in each group were assayed with Western blotting. The tissue blocks were rinsed 2 to 3 times with cold PBS buffer, placed in a mortar, and ground into powder. The powder was transferred to a $1.5 \mathrm{~mL}$ centrifuge tube, and oscillated. The tissues were bathed in ice for 30 min, during which they were repeatedly blown with a pipette to ensure complete cell lysis. This was followed by centrifugation at $12000 \mathrm{~g}$ for 10 min, and the protein content of the supernatant was measured. An appropriate amount of cytoplasmic protein extraction reagent $A$ and $B$ was mixed in $40: 1$ ratio, and $200 \mu \mathrm{L}$ of BCA mixture was added. The mixture was incubated at $37^{\circ} \mathrm{C}$ for $30 \mathrm{~min}$. The absorbance of the protein was read at $540 \mathrm{~nm}$ in a microplate reader, and the value obtained was multiplied by 10 to obtain the protein concentration of the original sample. Equal amounts of protein were subjected to SDS-PAGE, followed by transfer to PVDM, blocking and incubation with the appropriate primary antibodies overnight at $4^{\circ} \mathrm{C}$. This was followed by incubation with HRPconjugated secondary antibody at room temperature for $1 \mathrm{~h}$. The relative expressions were determined using gel imaging system, with GDAPH as reference gene. The experiment was repeated more than 3 times to reduce error.

\section{Statistical analysis}

Statistical analysis was done with SPSS 21.0 software package. Two-group comparisons were done with independent sample $t$-test, while single factor multi-sample test was used to compare multiple groups. Count data were compared using $X^{2}$ test. The comparison of grade data was performed with Ridit test. Values of $p<0.05$ were taken as indicative of statistical significance.

\section{RESULTS}

\section{Changes in FPG, FINS and HOMA-IR levels of rats}

As shown in Table 1, fasting blood glucose, fasting insulin, and insulin resistance index were markedly higher in model than in control rats, and were significantly higher in the inhibitortreated rats than in metformin rats $(p<0.05)$.

Table 1: Changes in FPG, FINS and HOMA-IR levels (mean \pm SD)

\begin{tabular}{lccc}
\hline Group & FINS (mU/L) & $\begin{array}{c}\text { FPG } \\
(\mathbf{m m o l} / \mathbf{L})\end{array}$ & HOMA-IR \\
\hline Control & $19.59 \pm 2.18$ & $4.68 \pm 0.37$ & $4.05 \pm 0.49$ \\
Model & $37.94 \pm$ & $6.85 \pm 0.18^{\mathrm{a}}$ & $11.46 \pm$ \\
& $4.07^{\mathrm{a}}$ & $1.84^{\mathrm{a}}$ \\
Inhibitor & $29.29 \pm$ & $5.62 \pm 0.21$ & $7.28 \pm 0.76$ \\
Metform & $1.39^{\mathrm{ab}}$ & $\mathrm{ab}$ & $\mathrm{ab}$ \\
in & $23.34 \pm$ & $5.25 \pm 0.29$ & $5.99 \pm 0.43$ \\
$F$ & $2.44^{\mathrm{abc}}$ & $\mathrm{abc}$ & $\mathrm{abc}$ \\
$P$-value & 175.382 & 226.941 & 179.512 \\
\hline
\end{tabular}

${ }^{\mathrm{a} P}<<0.05$, vs control rats; ${ }^{\mathrm{b}} p<0.05$, vs model rats; ${ }^{\mathrm{c}} p<$ 0.05 , vs inhibitor-treated rats

\section{Ovarian histomorphology of the rats}

In the control group, the number of granulosa cells in the follicles was more than that in the model group, and the number of granulosa cells and the formation of lutein were significantly reduced (Figure 1). In the inhibitor group, the number of granulosa cells and the formation of lutein were significantly improved, but were markedly reduced, when compared with the metformin group. In the metformin group, the number of granulosa cells and the formation of lutein were markedly improved. Cystic expansion of follicles was either absent or rare, and the number of granular layers was significantly increased.
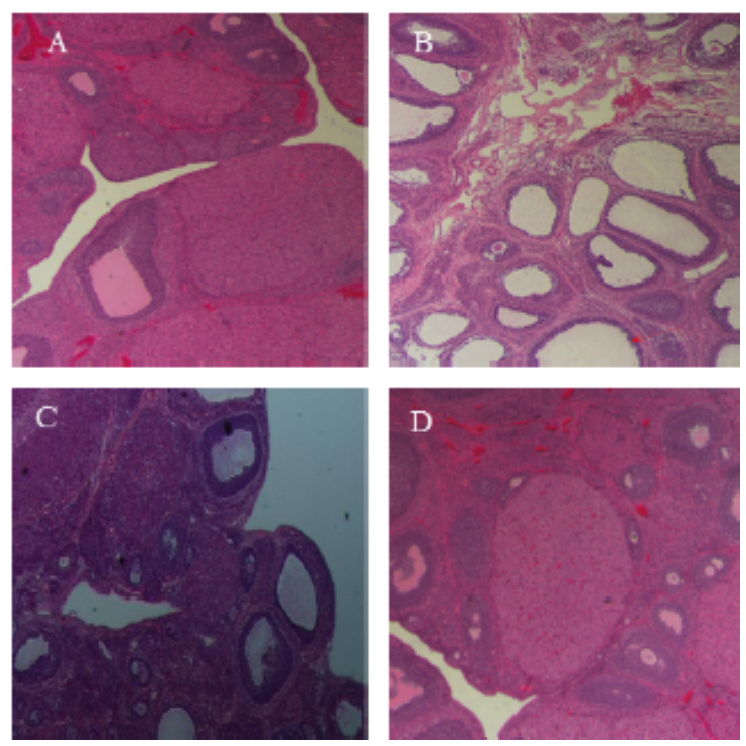

Figure 1: Comparison of ovarian histomorphology amongst the groups. A: control; B: model; $\mathrm{C}$ : + inhibitor; D: + metformin 


\section{LH, FSH, LH/FSH ratio and T levels}

Table 2 shows that $\mathrm{LH}, \mathrm{LH} / \mathrm{FSH}$ ratio and $\mathrm{T}$ levels in the model group were significantly raised, while the level of $\mathrm{FSH}$ was significantly low, relative to control; $\mathrm{LH}, \mathrm{LH} / \mathrm{FSH}$ ratio and $\mathrm{T}$ levels in inhibitor and metformin groups were significantly decreased, while FSH level was significantly raised, relative to model rats. In addition, $\mathrm{LH}, \mathrm{LH} / \mathrm{FSH}$ ratio and $\mathrm{T}$ levels were markedly reduced in metformin rats, relative to model rats, while FSH level was significantly raised $(p<0.05)$.

\section{Expression levels of PI3K and AKT in ovary and liver of rats}

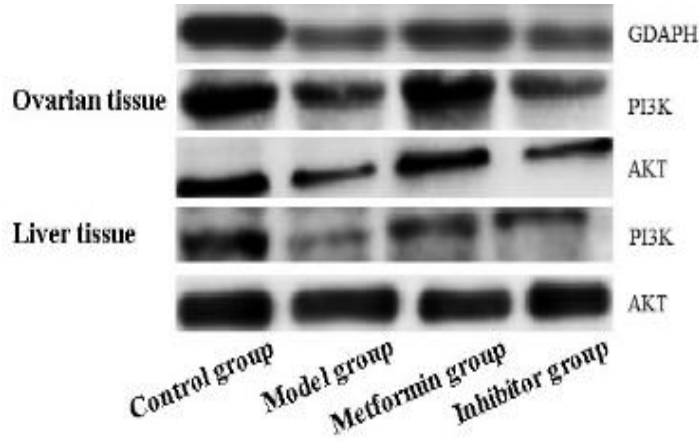

Figure 2: $\mathrm{PI} 3 \mathrm{~K}$ and AKT levels in ovaries and livers of rats in each group

The expression levels of $\mathrm{PI} 3 \mathrm{~K}$ and AKT in the ovary and liver were highest in the control group, but were lowest in the model group, while the corresponding expression levels in the inhibitor group were significantly lower than those in metformin group ( $p<0.05$; Figure 2 and Table 3).

\section{DISCUSSION}

Polycystic ovarian syndrome (PCOS) is the most common reproductive endocrine disorder in women of child-bearing age. Its clinical manifestations are diverse, and its pathological mechanism is complex. It is believed that the etiology is associated with factors such as genetic susceptibility, abnormalities in gonadotropin synthesis and metabolic disorders, amongst other factors. Insulin resistance (IR) is involved in the pathogenesis of PCOS [7]. At present, drug therapy is still the main treatment strategy for PCOS. However, due to limited access to clinical specimens, the use of animal models has become the major route of PCOSbased investigations. Many studies have shown that the PCOS-IR model in rats is similar to PCOS in human patients in terms of ovarian morphology, abnormal sexual hormone secretion, and glucose metabolism, and it is accompanied with IR $[8,9]$. Thus, this research involved investigation of the mitigating effect of metformin on polycystic changes associated with $\mathrm{IR}$ in PCOS rats.

Metformin is a biguanide oral hypoglycemic drug which delays glucose uptake from the gastrointestinal tract, increases the utilization of peripheral glucose by improving insulin sensitivity, and inhibits excessive glycogenesis in liver and kidney [10].

Table 2: Comparison of LH, FSH, LH / FSH, T levels in each group (mean \pm SD)

\begin{tabular}{ccccc}
\hline Group & LH $(\mathbf{m I U} / \mathbf{m L})$ & FSH (mIU/mL) & LH/FSH ratio & T (ng/mL) \\
\hline Control & $0.89 \pm 0.36$ & $5.47 \pm 1.66$ & $0.18 \pm 0.08$ & $0.59 \pm 0.15$ \\
Model & $12.89 \pm 1.41^{\mathrm{a}}$ & $2.54 \pm 1.26^{\mathrm{a}}$ & $5.46 \pm 1.02^{\mathrm{a}}$ & $4.08 \pm 1.41^{\mathrm{a}}$ \\
Inhibitor & $5.48 \pm 1.46^{\mathrm{ab}}$ & $3.56 \pm 1.08^{\mathrm{ab}}$ & $1.61 \pm 0.44^{\mathrm{ab}}$ & $1.69^{\mathrm{ab}} \pm 0.74^{\mathrm{ab}}$ \\
Metformin & $2.62 \pm 2.08^{\mathrm{abc}}$ & $4.94 \pm 1.02^{\mathrm{abc}}$ & $0.78 \pm 1.16^{\mathrm{abc}}$ & $1.14 \pm 0.29^{\mathrm{abc}}$ \\
$F$ & 261.694 & 21.605 & 174.521 & 71.531 \\
$P$-value & $<0.001$ & $<0.001$ & $<0.001$ & $<0.001$ \\
\hline
\end{tabular}

a, b, c $P<0.05$ ( $^{\mathrm{a}, \mathrm{b}, \mathrm{c}}$ vs control, model and inhibitor-treated rats, respectively)

Table 3: PI3K and AKT levels in ovary and liver of rats (mean \pm SD)

\begin{tabular}{lccc}
\hline Tissue & Group & PI3K & AKT \\
\hline \multirow{4}{*}{ Ovary } & Control & $0.97 \pm 0.09$ & $3.99 \pm 0.27$ \\
& Model & $0.36 \pm 0.13^{\mathrm{a}}$ & $2.11 \pm 0.35^{\mathrm{a}}$ \\
& Inhibitor & $0.49 \pm 0.04^{\mathrm{abc}}$ & $2.51 \pm 0.16^{\mathrm{ab}}$ \\
& Metformin & $0.69 \pm 0.09^{\mathrm{abc}}$ & $2.98 \pm 0.11^{\mathrm{abc}}$ \\
Liver & Control & $1.09 \pm 0.38$ & $2.71 \pm 0.12$ \\
& Model & $0.38 \pm 0.02^{\mathrm{a}}$ & $1.41 \pm 0.14^{\mathrm{a}}$ \\
& Inhibitor & $0.63 \pm 0.26^{\mathrm{ab}}$ & $1.84 \pm 0.09^{\mathrm{ab}}$ \\
& Metformin & $0.83 \pm 0.29^{\mathrm{abc}}$ & $2.12 \pm 0.18^{\mathrm{abc}}$ \\
\hline
\end{tabular}

$\mathrm{a}, \mathrm{b}, \mathrm{c} P<0.05(\mathrm{a}, \mathrm{b}, \mathrm{c} v \mathrm{vs}$ control, model and inhibitor-treated rats, respectively) 
Sturrock et al. have reported that metformin also reduced insulin levels, decreased IR, corrected disorders in reproductive endocrine levels and glucose metabolism in PCOS patients, and improved ovarian ovulation [11]

In IR, the efficiency of insulin in promoting glucose uptake and utilization is reduced for various reasons. In an attempt to maintain normal blood glucose levels, insulin is oversecreted in a compensatory way, resulting in hyperinsulinemia [12]. Insulin resistance occurs mostly in the skeletal muscle, myocardial muscle, liver, endometrium and other target organs. Studies in China and elsewhere have demonstrated that the etiology of PCOS-IR has an important relationship with the insulin signal pathway. The post-insulin receptor signal pathway comprises the PI3K/AKT signal route and the MAPK signal pathway. The PI3K/AKT signal pathway is key to post-insulin receptor signal transduction, and it is present in the islet of Langerhans $[13,14]$. It is implicated in the metabolic control of glucose in post-insulin receptor signal transduction $[15,16]$. Li et al [17] have reported that $\mathrm{PI} 3 \mathrm{~K} / \mathrm{AKT}$ signaling route is closely associated with ovarian function. When the activity of PI3K/AKT signaling pathway is decreased, insulin receptor is activated, and it directly acts on the follicular membrane cells, causing excessive androgen secretion, resulting in pituitary gonadotropin secretion disorder, and ultimately in excessive ovarian androgen secretion.

In this study, values of FPG, FINS, HOMA-IR, $\mathrm{LH}, \mathrm{T}, \mathrm{FSH}$ and $\mathrm{LH} / \mathrm{FSH}$ ratio were significantly higher in model rats than in control rats, while their corresponding levels were markedly lower in metformin rats than in model rats. However, after PI3K inhibitor was used, FPG, FINS, HOMA-IR LH, T and LH/FSH ratio were markedly increased, while FSH level, and the expressions of PI3K and AKT in ovary and liver were significantly decreased. These results demonstrate that metformin significantly reduced FPG, FINS, HOMA-IR, serum LH, T and LH/FSH ratio; and decreased polycystic ovarian changes and IR in PCOS rats. Moreover, metformin increased the expressions of PI3K and AKT in ovarian and liver tissues. The therapeutic effect of metformin on PCOS was inhibited by PI3K inhibitor. This finding is consistent with the report of Jin et al [18].

\section{CONCLUSION}

$\mathrm{LH}$ and $\mathrm{T}$ levels, and LH/FSH ratio in PCOS rats are markedly increased, relative to normal rats, while expressions of $\mathrm{PI} 3 \mathrm{~K}$ and $\mathrm{AKT}$ in $\mathrm{FSH}$, liver and ovary tissues are lower than their respective levels in normal rats. Thus, metformin can potentially mitigate polycystic ovarian changes and IR in humans via a mechanism which may be related to $\mathrm{PI} 3 \mathrm{~K} / \mathrm{AKT}$ insulin signaling pathway.

\section{DECLARATIONS}

\section{Conflict of interest}

No conflict of interest is associated with this work.

\section{Contribution of authors}

This study was done by the authors named in this article, and the authors accept all liabilities resulting from claims which relate to this article and its contents. The study was conceived and designed by Baimiao Wang. Lanyawen $\mathrm{Hu}$, Baimiao Wang, Yingli Tao collected and analyzed the data, while Lanyawen $\mathrm{Hu}$ and Baimiao Wang wrote the manuscript. All authors read and approved the manuscript for publication.

\section{Open Access}

This is an Open Access article that uses a funding model which does not charge readers or their institutions for access and distributed under the terms of the Creative Commons Attribution License (http://creativecommons.org/licenses/by/ 4.0) and the Budapest Open Access Initiative (http://www.budapestopenaccessinitiative.org/rea d), which permit unrestricted use, distribution, and reproduction in any medium, provided the original work is properly credited.

\section{REFERENCES}

1. Utiger RD. Insulin and the polycystic ovary syndrome. $N$ Engl J Med 2017; 130: 163.

2. Stener-Victorin $E$, Waldenström $U$, Tägnfors $U$, Lundeberg $T$, Lindstedt $G$, Janson PO. Effects of electro-acupuncture on anovulation in women with polycystic ovary syndrome. Acta Obstet Gynecol Scand 2015; 79(3): 180-188.

3. Wijeyaratne $\mathrm{CN}$, Balen $\mathrm{AH}$, Barth $\mathrm{JH}$, Belchetz PE. Clinical manifestations and insulin resistance (IR) in polycystic ovary syndrome (PCOS) among South Asians and Caucasians: is there a difference? Clin Endocrinol 2015; 57(3): 343-350

4. Makker A, Goel MM, Das V, Agarwal A. PI3K-Akt-mTOR and MAPK signaling pathways in polycystic ovarian syndrome, uterine leiomyomas and endometriosis: an update. Gynecol Endocrinol 2016; 28(3): 175-181.

Trop J Pharm Res, September 2020; 19(9): 1945 
5. Palomba $S$, Falbo A, Zullo $F$, Orio $F$ Jr. Evidence-Based and Potential Benefits of Metformin in the Polycystic Ovary Syndrome: A Comprehensive Review. Endocr Rev 2017; 30(1): 1-50.

6. World Health Organization. Principles of laboratory animal care. WHO Chron 1985; 39: 51-56.

7. Rocha ALL, Faria LC, Guimarães TCM, Moreira GV, Cândido AL, Couto CA, Reis FM. Non-alcoholic fatty liver disease in women with polycystic ovary syndrome: systematic review and meta-analysis. J Endocrinol Invest 2017; 40(12): 1-10.

8. Mehrabian F, Khani B, Kelishadi R, Kermani N. The prevalence of metabolic syndrome and insulin resistance according to the phenotypic subgroups of polycystic ovary syndrome in a representative sample of Iranian females*. J Res Med Sci 2016; 16(6): 763-769.

9. Yang S, Yang C, Pei R, Li C, Li X, Huang X, Wu S, Liu D. Investigation on the association of occupational stress with risk of polycystic ovary syndrome and mediating effects of HOMA-IR. Gynecol Endocrinol 2018; 34(11): $1-4$.

10. Mathur R, Alexander CJ, Yano J, Trivax B, Azziz R. Use of metformin in polycystic ovary syndrome. Am J Obstet Gynecol 2018; 199(4): 596-609.

11. Sturrock ND, Lannon B, Fay TN. Metformin does not enhance ovulation induction in clomiphene resistant polycystic ovary syndrome in clinical practice. Br J Clin Pharmacol 2015; 53(5): 469-473.

12. Abbott DH, Bacha F. Ontogeny of polycystic ovary syndrome and insulin resistance in utero and early childhood. Fertil Steril 2016; 100(1): 2-11.

13. Zhang MY, Wang BW, Liu S, Yang JP. Mechanism of propofol in inhibiting emt of breast cancer by controlling mir-21 expression. Acta Med Mediterr 2019; 35(6):31393145.

14. Karaman S, Erturk $K$, Serilmez $M$, Duranyilidiz D, Oral EN, Dagoglu N. Serum akt2 levels as a marker for lung cancer. Acta Med Mediterr 2019; 35(6): 3269-3272.

15. Zhang HY, Zhang YF, Han YK, Xue FX, Zhao XH, Zhang $X L$. Activation and significance of the PIJK/Akt pathway in endometrium with polycystic ovary syndrome patients. Zhonghua Fu Chan Ke Za Zhi 2016; 47(1): 19-23.

16. Zhao H, Zhou D, Chen Y, Liu D, Chu S, Zhang S. Beneficial effects of Heqi san on rat model of polycystic ovary syndrome through the PI3K/AKT pathway. Daru 2017; 25(1): 21

17. Li T, Mo H, Chen W, Li L, Xiao Y, Zhang J, Li X, Lu Y. Role of the PI3K-Akt Signaling Pathway in the Pathogenesis of Polycystic Ovary Syndrome. Reprod Sci 2016; 24(5): 646

18. Jin JJ. Effects of Metformin on PI3KJAKT Signal Pathway in Insulin Resistance of Polycystic Ovary Syndrome Rats. Guangzhou Med Univ 2017; 13(1): 22. 